Universidad de Lima

Escuela de Posgrado

Maestría en Derecho Empresarial

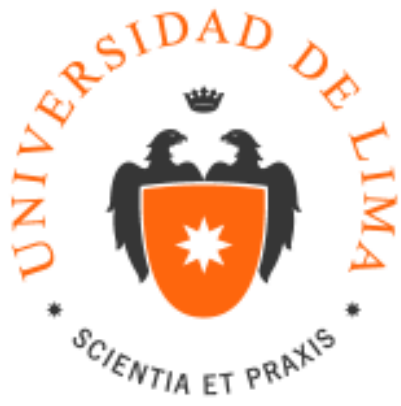

\title{
VULNERABILIDADES DE LA GESTIÓN DE RIESGO DE CLIENTES EN LA PREVENCIÓN DE LAVADO DE ACTIVOS EN EL CASO DE SOCIEDADES AGENTES DE BOLSA
}

Trabajo de investigación para optar el grado académico de maestro en Derecho Empresarial

Judith Alina Marroquin Quelopana

Código 19984428

Lima - Perú

Marzo 2016 


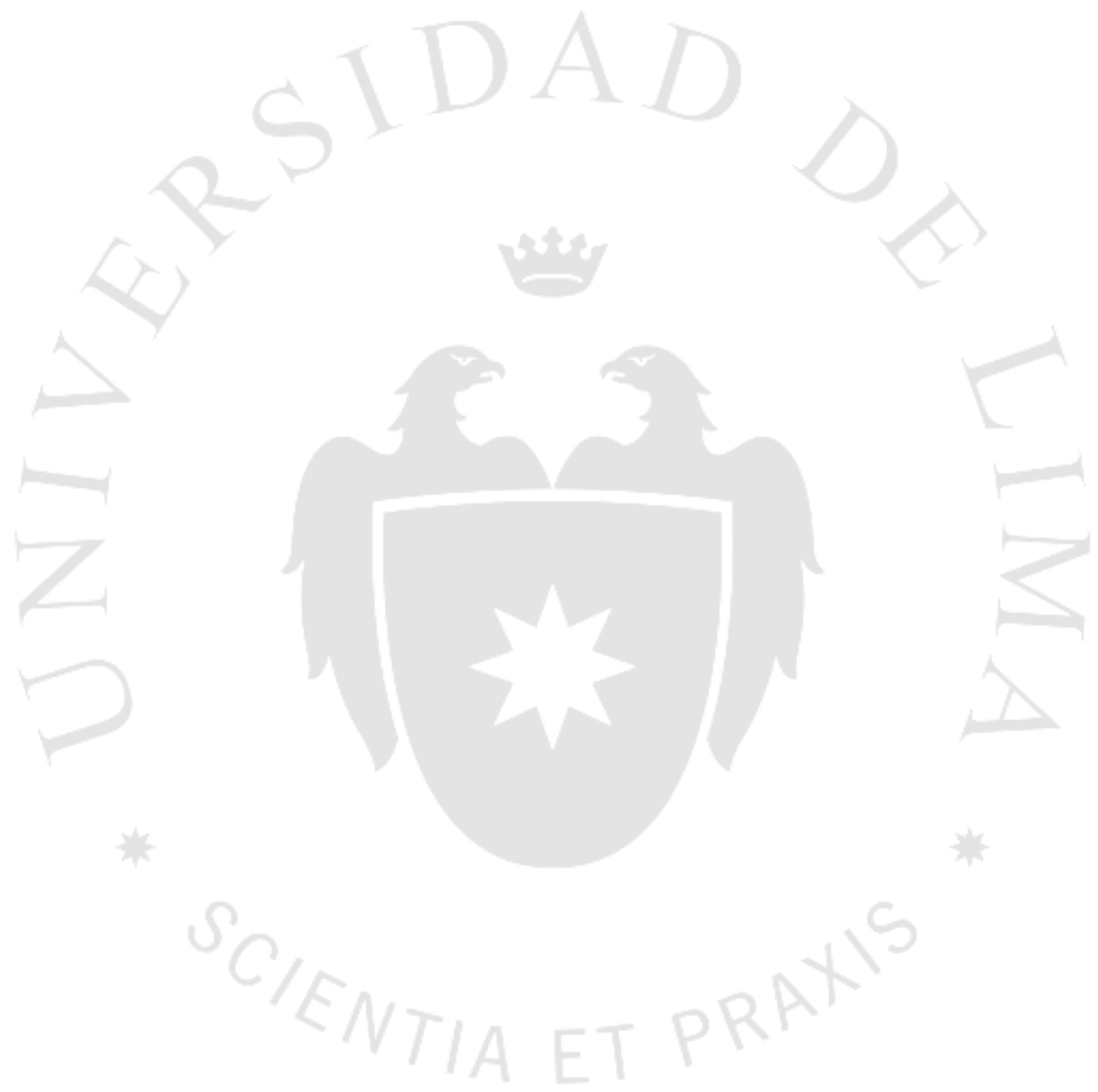




\section{VULNERABILIDADES DE LA GESTIÓN DE RIESGO DE CLIENTES EN LA PREVENCIÓN DE LAVADO DE ACTIVOS EN EL CASO DE SOCIEDADES AGENTES DE BOLSA}




\section{TABLA DE CONTENIDO}

\section{CAPÍTULO I: ASPECTOS PRELIMINARES}

\section{1}

1.1 Entendiendo el lavado de activos ............................................................

1.2 Efectos del lavado de activos: ..................................................................

1.3 El propósito de las regulaciones sobre lavados de activos .............................4

1.3.1 El rol del Grupo de Acción Financiera de Latinoamérica ..............................4

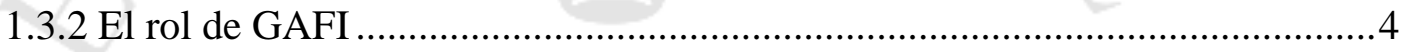

1.4 Marco normativo en el Perú en el ámbito de mercado de valores en la lucha

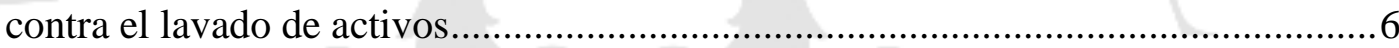

1.5 El rol de los supervisores nacionales en materia de lavados de activos ............6

1.5.1 El rol de la Unidad de Inteligencia Financiera ...................................6

1.5.2 El rol del Oficial de Cumplimiento .........................................................

\section{CAPÍTULO II: RIESGO DE LAVADO DE ACTIVOS EN EL MERCADO DE}

VALORES .............................................................................................................................10

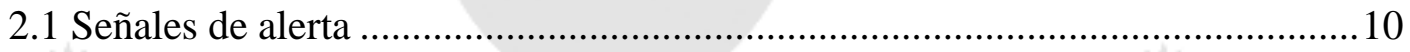

2.2. Señales de Alerta en el Mercado de Valores ...................................................10

2.3 Tipologías de lavados de activos en el mercado de valores ............................11

2.3.1 El Insider trading o uso de información privilegiada ................................ 12

2.3.2 Manipulación de Mercado ..................................................................... 13

2.4 El enfoque basado en riesgos en la prevención del lavado de activos ..............15

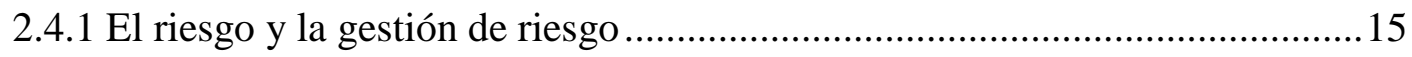

2.5 Deficiencias en la supervisión basado en riesgos ........................................ 17 


\section{CAPÍTULO III: PROPÓSITOS, BENEFICIOS Y RETOS DEL ENFOQUE}

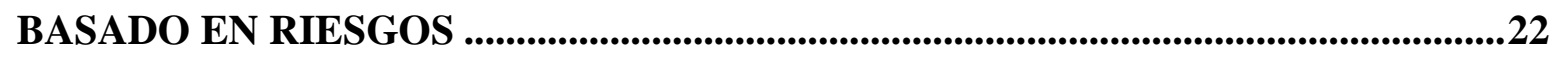

3.1 El GAFI y el enfoque basado en riesgos .........................................................22

3.2 Principios para el diseño de un enfoque basado en riesgos ................................22

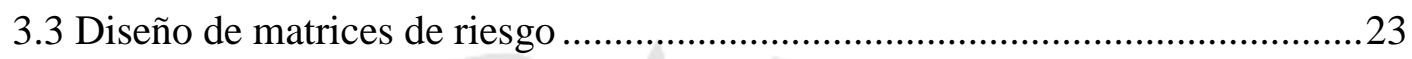

3.4 Implementación de controles internos bajo el enfoque basado en riesgos .........25

CAPÍTULO IV: EL RIESGO DEL CLIENTE .........................................................28

4.1 Relevancia del Conocimiento del Cliente en el enfoque basado en riesgo .......28

4.1.1 ¿Qué es la debida diligencia en el conocimiento del cliente? .........................28

4.2 Determinación del perfil de riesgo del cliente.......................................................30

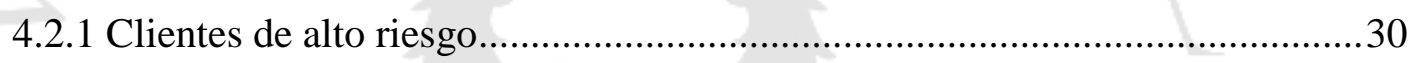

4.2.2 Personas políticamente expuestas..................................................................

4.3 Procedimientos de debida diligencia reforzada ................................................32

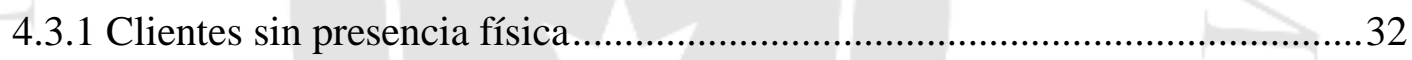

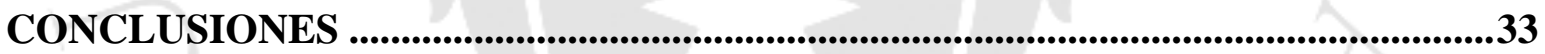

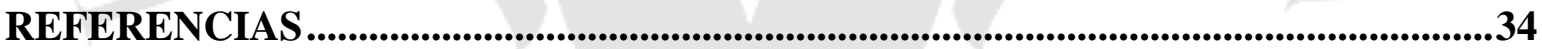




\section{ÍNDICE DE FIGURAS}

Figura 2. 1 Lavado de Activos en el Mercado de Valores................................................ 12

Figura 2. 2 Número de Reportes de Operaciones sospechosas recibidos anualmente .........19

Figura 2. 3 Reporte de operaciones sospechosas - Participación por tipo de sujeto obligado

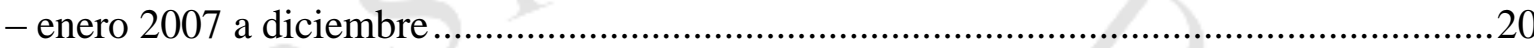

Figura 2. 4 Reporte de Operaciones Sospechosas - Participación por tipo de sujeto obligado

- últimos 12 meses a diciembre del 2015 .................................................................21

Figura 3. 1 Administración del Riesgo de LAFT - SABs...............................................24

Figura 3. 2 Resultados del Enfoque por riesgos para la FLAFT ....................................24

Figura 3. 3 Administración del Riesgo de LAFT ........................................................25 


\section{INTRODUCCIÓN}

La actividad del mercado de valores, es una actividad regulada y sujeta a un nivel de supervisión que requiere de nuevos retos y exigencias.

Los riesgos son parte inherente de las operaciones de todos aquellos entes que operan en el mercado de valores, razón por la cual contar con una eficiente administración de los mismos constituye un elemento esencial en la gestión de la entidad. La prevención de los riesgos será siempre mejor que reaccionar cuando estos ya hayan ocurrido.

Las entidades para lograr sus objetivos requieren fidelizar clientes, a los cuales se les ofrece una variedad de productos o servicios a través de diferentes canales de distribución que operan en diferentes zonas geográficas. Por ejemplo un cliente que tiene casinos es de mayor riesgo que uno que es veterinario. Igualmente, el riesgo es mayor si se opera en zonas propensas a la comercialización de cocaína o contrabando.

En el marco de la prevención de lavado de activos, un intermediario de valores debe contar con un esquema de gestión que le permita prevenir que la entidad sea utilizada para fines de lavados de activos y para ellos es vital entender la operatividad del negocio, identificar el perfil de clientes que acceden al mercado a través de la entidades, los riesgos asociados a los productos que se ofrecen, así como los riesgos derivados de los canales de distribución y las zonas geográficas en las que realiza operaciones la entidad.

La normativa vigente exige, la aplicación de medidas de debida diligencia que permitan conocer al cliente bajo un enfoque preventivo antes que reactivo dentro de un marco de gestión adecuado.

$\mathrm{Si}$ los clientes son los que permiten a las empresas generar volúmenes de transacciones haciéndolas rentables y con un crecimiento sostenido durante el tiempo, resulta fundamental que las entidades instauren y apliquen una estricta Política de Conocimiento del Cliente, que se fundamente en la obtención, la verificación de la misma, la actualización de dicha información y el seguimiento continuo al comportamiento del 
cliente en términos de las operaciones que realiza, los productos que utiliza, los movimientos de dinero que ejecuta, entre otros.

La necesidad de contar con un modelo que nos permita tener lineamientos de gestión, desde la óptica normativa hasta lograr la eficiencia de los procesos, permitirá aplicar acciones para mitigar estos riesgos, orientando los recursos de forma efectiva y aplicando medidas preventivas acordes con los grados de exposición.

Debemos ser incansables en nuestra lucha contra el lavado de activos, dado a que estamos expuestos a las consecuencias negativas que acarrea el lavado, no solo de carácter interno sino también el riesgo que implica para la reputación como Nación. 


\section{CAPÍTULO I: ASPECTOS PRELIMINARES}

\subsection{Entendiendo el lavado de activos}

La Convención de las Naciones Unidas fue el instrumento multilateral en el que se delinearon nuevas estrategias que afectarían la estructura productiva y el financiamiento de organizaciones criminales. A partir de dicha Convención se empezaron a diseñar sistemas normativos con la finalidad de consolidar la regulación en todos los aspectos, uno de naturaleza administrativa, relacionada con la prevención de esas conductas y otro de ámbito penal cuya finalidad es la represión punitiva de los mismos.

Es en este escenario, que surgió la necesidad de tipificar y sancionar el delito de lavado de activos, se promovió que los Estados configuraran un delito autónomo con tipificación y pena, tal como lo afirma Prado Saldarriaga (2007):

La Convención exigió que los gobiernos signatarios declararan delito penal el lavado de dinero relacionado con drogas; también requirió reafirmar su autoridad legal para confiscar las ganancias obtenidas por delitos penales; y suprimir el secreto bancario como motivo para negarse a actuar contra el lavado de dinero. (p. 4)

De otro lado, la identificación de la fuente de dinero utilizado en una operación comercial es el aspecto más importante en la prevención de lavado de activos, para ello se deben utilizar mecanismos como recabar la información que brinda inicialmente el cliente, al inicio de la relación comercial, será importante para determinar si es que detrás de la operación existe una tercera persona o testaferro.

Caparros nos instruye sobre el origen del dinero cuando señala:

Hablar del blanqueo o del lavado de capitales supone referirse implícitamente a la previa negritud o suciedad de los mismos. Normalmente vinculados al dinero, los calificativos de negro o sucio son empleados en la jerga económica y financiera para expresar el carácter irregular de unos determinados bienes. (como se citó en Arbulú Ramirez, 2014, p.7) 
El lavado de activos se desarrolla en el ámbito preventivo, que tiene por finalidad recolectar y procesar información que es comunicada por los sujetos obligados a la Unidad de Inteligencia Financiera (UIF) a través de un documento denominado Reporte de Operaciones Sospechosas (ROS), quienes al realizar el análisis de la información remitida determinarán si dicha información amerita ser enviada al Ministerio Público para que se realice una investigación penal.

El lavado de activos es un proceso que se desarrolla en tres etapas, etapa de colocación u ocultamiento también conocida como la fase de recolección de los bienes del dinero en efectivo o del prelavado; etapa de intercalación que busca cortar la cadena de evidencias ante eventuales investigaciones sobre el origen del dinero fase de conversión y fase de integración a la economía oficial (Prado Saldarriaga, 2007, p. 26).

Las etapas del lavado de activos se clasifican en:

Etapa de Colocación, etapa en la que se introducen fondos procedentes de actividades ilegales en el sistema financiero, mediante depósitos u otros mecanismos.

Etapa de Estratificación, etapa en la que se separa los fondos de manera escalonada en una serie de transacciones financieras complejas con la finalidad de ocultar el origen de la actividad delictiva.

Etapa de Integración, es el proceso de utilizar una operación aparentemente legítima y reintegrarla al sistema financiero con la finalidad de que los fondos regresen al criminal.

La tipología o los métodos más usados, para el lavado de activos se realizan mediante:

a) Estructuración de depósitos: (pitufeo) mediante la apertura de varias cuentas en diferentes entidades financieras que para ser detectadas requerirán que las entidades financieras consoliden las operaciones realizadas por montos inferiores a las operaciones exigidas en el registro en diferentes oficinas de la institución. 
b) Compañías fachada; son empresas legalmente constituidas que realizan una actividad comercial y que es utilizada para el lavado de fondos producto de actividades ilícitas.

c) Compañías ficticias; este tipo de compañías no realizan actividades comerciales, son utilizadas para disfrazar el movimiento de recursos ilícitos, aprovechando la cobertura confidencial o disfrazando a sus verdaderos dueños por medio de una representación nominal.

d) Uso de la banca extranjera; se constituyen en países en los que la reserva o secreto bancario son estrictos y hacen imposible conocer a los verdaderos clientes.

\subsection{Efectos del lavado de activos:}

Según la UIAF (2014), los efectos del lavado de activos se evidencian cuando afecta la información con la que cuentan los agentes económicos y a los que se les envía señales equivocadas sobre las condiciones del mercado, aspectos fundamentales para la toma de decisiones de producción, inversión y la eficiente asignación de recursos.

Cuando se comprueban las distorsiones de las condiciones de competencia, debido a que la lógica del lavador le permite operar incluso en condiciones económicas desfavorables, sectores económicamente ineficientes o no rentables y precios por debajo de los costos de producción o comercialización. (UIAF, 2014)

Cuando afecta la integridad, reputación y estabilidad del sistema financiero, reduciendo la confianza del público en este sistema, en sus reguladores y en los agentes prestadores de servicios financieros; en la inyección de capitales de origen ilícito en algunos sectores de la economía, tales como el exportador, inmobiliario y bursátil han facilitado la generación de condiciones artificiales de bienestar no sostenibles. (UIAF, 2014) 
Y finalmente, porque frena el desarrollo económico de un país, reduciendo la recaudación tributaria, además de tener que destinar recursos públicos para mitigar el lavado de dinero.

Es vital tomar conciencia de los riesgos que enfrenta cada actividad, profundizar en el examen de las vulnerabilidades de cada sector, y establecer las medidas preventivas que puedan ser eficaces de acuerdo con la lógica de cada mercado.

\subsection{El propósito de las regulaciones sobre lavados de activos}

\subsubsection{El rol del Grupo de Acción Financiera de Latinoamérica}

El Grupo de Acción Financiera de Latinoamérica (Gafilat) es una organización intergubernamental que agrupa a 16 países de América del Sur, Centroamérica y América de Norte para combatir el lavado de dinero y la financiación del terrorismo, a través del compromiso las políticas nacionales contra delitos y los mecanismos de cooperación entre los países miembros (Grupo de Acción Financiera Internacional [GAFI], s.f.).

Gafilat fue creado a semejanza del Grupo de Acción Financiera Internacional (GAFI) adhiriéndose a las 40 Recomendaciones del GAFI como estándar internacional más reconocido contra el lavado de dinero y la financiación del terrorismo, y el desarrollo de Recomendaciones propias de mejora de las políticas nacionales para luchar contra estos delitos. (GAFI, 2012, p. 6)

Gafilat apoya a sus miembros en la implementación de las 40 Recomendaciones en ley nacional y en la creación de un sistema regional de prevención contra el lavado de activos y el financiamiento del terrorismo (GAFI, s.f.).

\subsubsection{El rol de GAFI}

El mandato del GAFI es fijar estándares y promover la implementación efectiva de medidas legales, regulatorias y operativas para combatir el lavado de activos, el financiamiento del 
terrorismo y otras amenazas a la integridad del sistema financiero internacional. En colaboración con otras partes involucradas a nivel internacional, el GAFI también trata de identificar vulnerabilidades a nivel nacional para proteger el sistema financiero internacional de usos indebidos. (GAFI, 2012, p. 6)

Las Recomendaciones del GAFI constituyen medidas que los países deben implementar para combatir el lavado de activos, financiamiento del terrorismo, y de la proliferación de armas de destrucción masiva.

Los países tienen diversos marcos legales, administrativos y operacionales y diferentes sistemas financieros, por lo cual no pueden tomar todos medidas idénticas contra estas amenazas. Por lo tanto, las Recomendaciones del GAFI, fijan un estándar internacional que los países deberían implementar por medio de medidas adaptadas a sus circunstancias particulares. Las Recomendaciones del GAFI establecen medidas esenciales que los países deben implementar para:

a) Identificación de los riesgos;

b) Luchar contra el lavado de activos; financiamiento del terrorismo y financiamiento de la proliferación de armas de destrucción masiva;

c) Aplicar medidas preventivas para el sector financiero

d) Establecer poderes y responsabilidades y otras medidas institucionales;

e) Mejorar la transparencia y la disponibilidad de la información de titularidad de beneficio de las personas y estructuras jurídicas; y

f) Facilitar la cooperación internacional. (Gafilat, 2014, p. 17)

El enfoque basado en riesgo permite que los países adopten medidas más flexibles para orientar los recursos de manera más efectiva y aplicar medidas preventivas acordes con la naturaleza de los riesgos para focalizar sus esfuerzos de manera más efectiva (GAFI, 2012).

Para Melgar el "principio conozca a su cliente" se complementa con el conocimiento del mercado, en donde el cliente se desenvuelve de manera tal que permita a las empresas del sistema financiero conocer los productos o servicios ofrecidos por el 
cliente así como los niveles de demanda, precios y comportamientos del mercado que le generan su actividad y negocios. (como se citó en Arbulú Ramírez, 2014, p. 135)

\subsection{Marco normativo en el Perú en el ámbito de mercado de valores en la lucha contra el lavado de activos}

En el ámbito de Mercado de Valores, siendo la Superintendencia del Mercado de Valores la llamada a ejercer la función de control y supervisión del sistema de prevención de lavado de activos y financiamiento del terrorismo, se expidió una norma respecto de los sujetos obligados bajo el ámbito de supervisión, la que se encuentra contenida en la Resolución CONASEV N ${ }^{\circ}$ 033-2011-EF-94.01.1 de fecha 09 de mayo de 2011, que fue concebida a efectos de prevenir el riesgo de lavado de activos mediante procesos como identificación, monitoreo, evaluación y control de riesgos.

\subsection{El rol de los supervisores nacionales en materia de lavados de activos}

\subsubsection{EI rol de la Unidad de Inteligencia Financiera}

La Unidad de Inteligencia Financiera-Perú (UIF-Perú) fue creada por Ley N 27693 en abril del año 2002, posteriormente modificada por las Leyes $\mathrm{N}^{\circ} 28009$ y $\mathrm{N}^{\circ} 28306$, su reglamento fue dado por Decreto Supremo No 163-2002-EF posteriormente modificado por Decreto Supremo No 018-2006-JUS de julio del 2006, subsiguientemente fue incorporada como Unidad Especializada a la Superintendencia de Banca, Seguros y Administradoras Privadas de Fondos de Pensiones, mediante Ley No 29038 el 12 de junio del 2007, en la actualidad tiene autonomía funcional y técnica.

La UIF-Perú es la Agencia Central Nacional encargada de cumplir y hacer cumplir las disposiciones establecidas por la Ley, además de ser el contacto de intercambio de información a nivel internacional en la lucha contra el Lavado de Activos y el Financiamiento del Terrorismo y, es responsable de liderar el Sistema Anti Lavado y contra 
el Financiamiento del Terrorismo en el Perú - SILAFIT Perú - y diseñar el Plan Nacional de Lucha Contra el Lavado de Activos y Financiamiento del Terrorismo.

Es la encargada de recibir, analizar, tratar, evaluar y transmitir información para la detección del Lavado de Activos y del Financiamiento del Terrorismo; coadyuvar a la implementación por parte de los Sujetos Obligados del Sistema Nacional de Activos y Financiamiento del Terrorismo para detectar Operaciones Sospechosas de Lavado de Activos y Financiamiento del Terrorismo. (Unidad de Inteligencia Financiera, 2006, p. 26)

Las funciones que cumple la UIF-Perú dentro del ámbito operativo, es realizar un tratamiento de reportes de operaciones sospechosas, utilizando información de diversas fuentes para identificar posibles casos de lavado de activos; en el ámbito estratégico, deberá identificar las diferentes tipologías y patrones de comportamiento y generación de estadísticas y, en el ámbito de cumplimiento implementar actividades de difusión y capacitación, así como supervisión de cumplimiento de las normas, esta supervisión será directa respecto de los sujetos obligados que no se encuentran dentro del ámbito de competencia de un supervisor como son las joyerías, inmobiliarias, casas de cambio y anticuarios entre otros.

Asimismo, en cuanto al ámbito de cooperación tenemos que la coordinación interinstitucional nacional e internacional es vital en investigaciones conjuntas en las que autoridades como el Ministerio Publico y el Poder Judicial se verán beneficiados con la incorporación de la información especializada brindada por la UIF-Perú y de sus homólogas a nivel internacional.

\subsubsection{El rol del Oficial de Cumplimiento}

El Oficial de cumplimiento es la persona natural que colabora en la implementación del sistema de prevención del LAFT y es responsable de vigilar su funcionamiento, podrá ser el propio obligado cuando éste sea persona natural; cuando sea persona distinta al sujeto obligado se requiere que sea de su absoluta confianza, dependerá laboralmente del sujeto obligado y tendrá autonomía en el ejercicio de sus responsabilidades y funciones asignadas. 
De otro lado, cuando el sujeto obligado sea persona jurídica la designación del oficial de cumplimiento le corresponde al Directorio, el Gerente General u órgano equivalente y su designación será comunicada al Superintendente Adjunto de la IUF-Perú en un plazo no mayor de 5 días hábiles de producida, adjuntando la documentación respectiva.

El Oficial de cumplimiento es el encargado de ejercer la política global del Estado frente a los particulares, su función no está ceñida únicamente a emitir los reportes de operaciones sospechosas sino velar por que la empresa que lo designo cumpla con la normatividad sobre la materia, dentro de sus obligaciones tenemos que debe verificar e investigar sobre la identidad del cliente, sus antecedentes en los sistemas llámese RENIEC, SUNAT, SUNARP, INFOCORP, registros de negociaciones y listas negras de los organismos internacionales como la DEA, FBI, para tener la certeza de que los fondos utilizados sean lícitos, para descartar que nos encontramos frente a clientes de alto riesgo, clasificarlos como habituales, ocasionales. Todos estos datos permitirán que el oficial de cumplimiento se forme un criterio y establecer un perfil de cliente, debiendo monitorearlos y definir el momento en que deja de ser un registro más para convertirse en un alerta de operación sospechosa.

Pérez Lamela (2006) define al Reporte de Operaciones Sospechosas como el instrumento de comunicación exigido por las resoluciones de la Unidad de Información Financiera a los sujetos obligados a informar. Añade si bien a simple vista pareciera un formulario operativo que integra el régimen de cumplimiento, donde se perfecciona ante la autoridad competente el deber de informar establecido por el ordenamiento legal, considera que es una herramienta fundamental en el proceso de prevención, no solo por el motivo enunciado precedentemente de dar cumplimiento a la exigencia normativa, sino que además constituye el elemento documental definitivo que permite al sujeto obligado demostrar que ha cumplido su deber con la debida diligencia que exige la naturaleza de la obligación, resguardándolo a futuro de cualquier contingencia por eventuales daños y perjuicios (p.149). 
El Oficial de cumplimiento una vez que, con toda la información recabada, determina que clientes y cuales son más riesgosos que otros, establecerá una sistematización del riesgo para su representada.

Igualmente debe elaborar procedimientos con el objetivo de conocer e identificar detalladamente a sus empleados, además de instruirlos y capacitarlos permanente y adecuadamente para que el modelo de lucha contra el Lavado de Activos funcione óptimamente. 


\section{CAPÍTULO II: RIESGO DE LAVADO DE ACTIVOS EN EL MERCADO DE VALORES}

\subsection{Señales de alerta}

La definición del término "alerta" implica referirse a un indicio que permite establecer que una determinada operación x podría destinarse para el lavado de activos, se evidencia en la información recabada por el sujeto obligado o por la documentación brindada por el cliente, como por ejemplo el reporte de una notificación en la que se refiere al domicilio fiscal como no ubicado o cuando el cliente no brinda la información o esta es vaga o imprecisa o si el cliente realiza una operación de depósito a terceras personas, en efectivo, por una cantidad significativa sin estar registrado en la SUNAT, son diversas y cada vez más elaboradas las técnicas que utilizan las personas para estructurar el lavado y sobre todo hacerlo invisible al ojo del regulador.

Hoy en día es más sencillo detectar las señales de alerta utilizando los mecanismos electrónicos que permitirán con el cruce de información, tener indicios que nos permitirán desvirtuar esta condición.

De otro lado, existen puntos vulnerables que en materia financiera son ampliamente conocidos, vías usuales que tienen los bancos para entradas y salidas de dinero, que a decir de Prado Saldarriaga (2007) son el punto de entrada de dinero metálico en los bancos (depósitos); los flujos internacionales de dinero metálico de un banco a otro; y, las transferencias de dinero metálico dentro o desde el sistema bancario (p. 56).

\subsection{Señales de Alerta en el Mercado de Valores}

La experiencia del regulador ha permitido identificar como señales de alerta de operaciones inusuales, aquellas en las que se demuestren que la actividad que desarrolla el cliente no es congruente con sus negocios habituales, sea el caso de transacciones realizados en efectivo 
y no utilizando mecanismos usuales como cheques de gerencia, depósitos en cuenta de clientes, que no se justifican, en el rubro en el que se desarrollan.

Otro caso típico es el del empleado que tiene un ingreso mensual y/o quincenal acorde al mercado, pero que en su cuenta bancaria se registran depósitos por sumas de dinero que están por encima de los ingresos registrados por la actividad que desempeña; adquisiciones de productos, servicios que largamente supera el ingreso mensual del trabajador.

Entre las señales de alerta más utilizadas tenemos:

- Transacciones inusuales de valores y actividad en la cuenta, compra a precio alto y vende a un tercero con considerables pérdidas.

- El uso de empresas ficticias para comprar acciones de empresas públicas.

- El Cliente no está familiarizado con el rendimiento y especificaciones de un producto financiero, no obstante, insiste en invertir en él.

- Compra de inversiones a largo plazo seguida poco después por liquidación, sin importar los costos y penalidades por venta prematura.

- Empleados bandoleros; que parecen disfrutar de un lujoso estilo de vida inconsistente con su nivel de ingreso laboral.

- El empleado descuidado, que se encuentra sujeto a intensas demandas de trabajo, tales como ventas y metas de producción, que resultan en que pase por alto riesgos de lavado de dinero.

\subsection{Tipologías de lavados de activos en el mercado de valores}

El sector mercado de valores, es el/único sector que puede ser utilizado tanto para introducir lavado de fondos ilícitos, así como para generar fondos ilícitos dentro de la propia industria a través de actividades fraudulentas, tales como:

- Información privilegiada (insider trading); y,

- Manipulación de mercado 
- Son señales de alerta, que se deben tener en cuenta en el manejo de información privilegiada:

- Cuando el cliente realiza una compra o venta grande de una acción, o la opción de una acción, poco antes de que se difundan las noticias que afectan el precio de la acción.

- Cuando el cliente tiene amigos o familiares que trabajan para el emisor de acciones.

- Cuando los patrones de operación de un cliente sugieren que él o ella pueden tener información privilegiada.

Figura 2. 1

Lavado de Activos en el Mercado de Valores

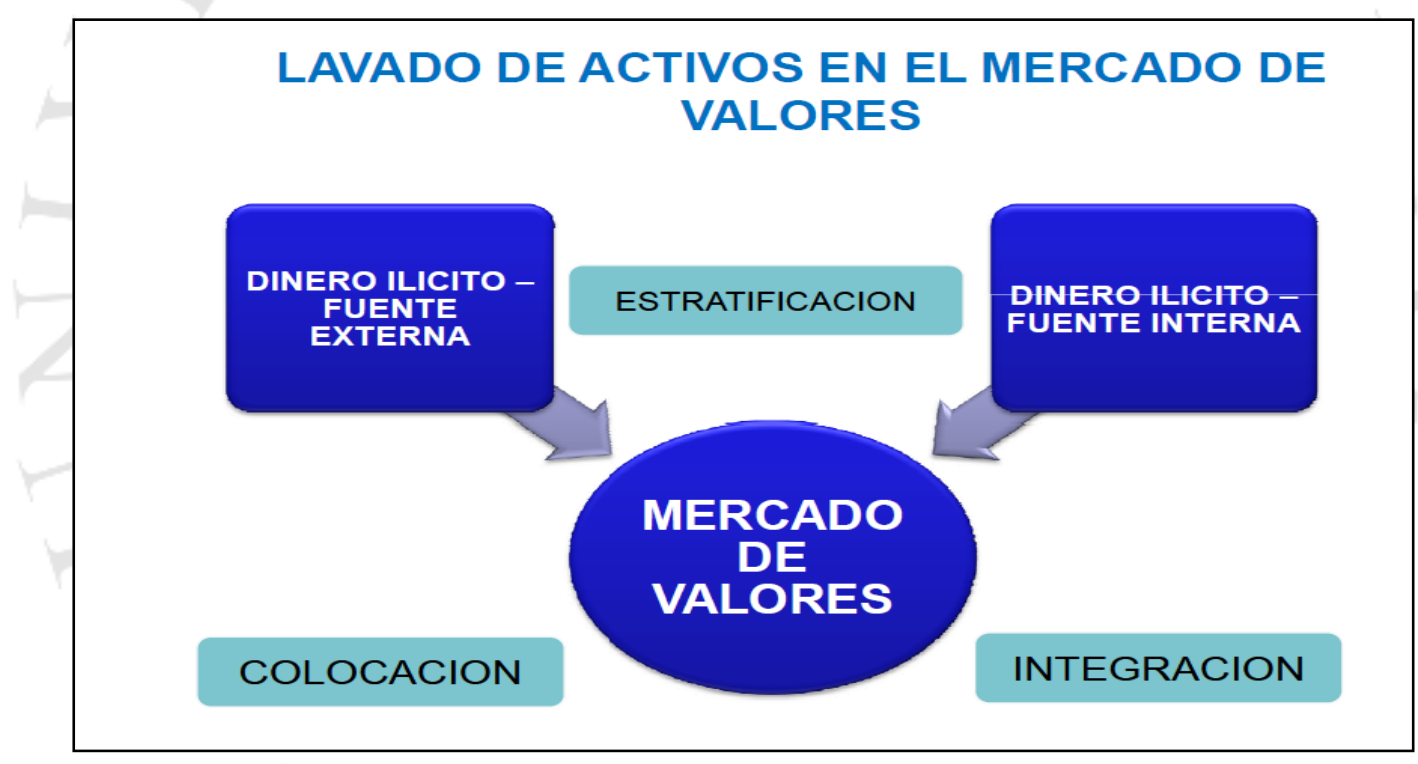

\subsubsection{El Insider trading o uso de información privilegiada}

Se tipifica cuando determinada información es utilizada para beneficio propio, directo o indirecto, dicha información no está al alcance del público en general, definitivamente si fuese conocida incidiría en la cotización de un valor.

El artículo $40^{\circ}$ de la Ley del Mercado de Valores (Decreto Legislativo N. ${ }^{\circ}$ 861), define a la información privilegiada: 
Como cualquier información referida a un emisor, a sus negocios o a uno o varios valores por ellos emitidos o garantizados, no divulgada al mercado y cuyo conocimiento público, por su naturaleza, sea capaz de influir en la liquidez, el precio o la cotización de los valores emitidos. Comprende, asimismo, la información reservada a que se refiere el Artículo $34^{\circ}$ de la Ley y aquélla que se tiene de las operaciones de adquisición o enajenación a realizar por un inversionista institucional en el mercado de valores, así como aquélla referida a las ofertas públicas de adquisición.

Un caso puntual fue el hecho de que la Superintendencia del Mercado de Valores (SMV) sancionara a 8 personas naturales y a Promotores e Inversiones Investa S.A. Sociedad Agente de Bolsa por el uso indebido de información privilegiada, respecto de las operaciones de compra y venta de valores realizados por Seguro Social de Salud (EsSalud) en el mercado de valores, contraviniendo lo dispuesto por el artículo $43^{\circ}$, incisos a) y c) de la Ley de Mercado de Valores, con multas de 300 UIT's.

\subsubsection{Manipulación de Mercado}

Con respecto a la manipulación de mercado en nuestra legislación no existe una definición sobre manipulación de mercado, el artículo $12^{\circ}$ de la Ley de Mercado de Valores señala, que está prohibido todo acto, omisión, práctica o conducta que atente contra la integridad o transparencia del mercado, literalmente prohíbe:

a) Efectuar transacciones ficticias respecto de cualquier valor, sea que las operaciones se lleven a cabo en mecanismos centralizados o a través de negociaciones privadas, así como efectuar transacciones con valores con el objeto de hacer variar artificialmente los precios, sin perjuicio de lo establecido en el inciso f) del Artículo $194^{\circ}$.

Se entiende por transacción ficticia aquélla en la cual no se produce una real transferencia de valores, de los derechos sobre ellos u otras semejantes, o aquéllas efectuadas a precios evidentemente distintos a los del mercado; $\mathrm{y}$,

b) Efectuar transacciones o inducir a la compra o venta de valores por medio de cualquier acto, práctica o mecanismo engañoso o fraudulento. 
c) Que los directores, funcionarios y trabajadores de las bolsas de valores y de las demás entidades responsables de la conducción de mecanismos centralizados, así como de las instituciones de compensación y liquidación y de la SMV efectúen transacciones con valores mobiliarios o incrementen sus tenencias previas de valores, si las tuvieran, salvo en los casos de:

1. Acciones liberadas.

2. Acciones que se suscriban en ejercicio del derecho de suscripción preferente establecido en la Ley General de Sociedades.

3. Los valores que provengan de la condición de usuario de un servicio público o hayan sido adquiridos para fines de desgravamen tributario.

En todo caso, tales personas deberán abstenerse de participar en las juntas generales de accionistas de las sociedades en las que posean acciones y que se encuentren sometidas al control y supervisión de la SMV. (Resolución Conasev Nº 033-2011-EF/94.01.1.)

La manipulación de mercado, es el intento deliberado de interferir con el funcionamiento libre y justo del mercado, se puede ejecutar de dos formas:

- Informativa: divulgación de información falsa o tendenciosa para fines de inversión; $\mathrm{y}$,

- Operativa: realización de transacciones de manera deliberada para interferir con el funcionamiento libre del mercado y de crear apariencias falsas o engañosas con respecto al precio de mercado de un valor, que puede llevarse a través del Churning, que no es más que la ejecución de las operaciones de una cuenta de un cliente por un intermediario con la finalidad de generarse comisiones por sus servicios prestados.

La regulación contra el abuso de mercado, de acuerdo a la Ley Orgánica de la SMV (Decreto Ley $\mathrm{N}^{\circ}$ 26126), se fundamenta en la necesidad de propiciar un desarrollo ordenado del mercado de valores, que ofrezca a los inversionistas información oportuna, suficiente y confiable para la toma de decisiones en igualdad de oportunidades sin la intervención de factores ajenos que afecten la libre formación de precios. 


\subsection{El enfoque basado en riesgos en la prevención del lavado de activos}

La gestión de riesgo en el lavado de activos es un proceso continuo que tiene por finalidad optimizar esfuerzos y recursos del sujeto obligado orientándolos hacia los riesgos identificados; es inherente al sistema de lavado de activos y está compuesta por cuatro etapas:

Etapa de identificación; los riesgos deben identificarse, de acuerdo a su actividad económica para ello hay que equilibrar qué factores de riesgo se debe utilizar como clientes, productos, servicios, canales de distribución y ubicación geográfica

Etapa de evaluación; se deben evaluar y establecer probabilidades de ocurrencia de estos, así como el impacto que tendrían en el sujeto obligado en el caso que se materialice. Deberá elaborarse una matriz de riesgo.

Etapa de control; luego de evaluar los riesgos identificados, se debe elaborar, adoptar y aplicar las políticas, procedimientos y controles que permitan mitigarlos.

Etapa de monitoreo; consiste en revisar la efectividad de las políticas, procedimientos y controles implementados en la etapa de control.

\subsubsection{El riesgo y la gestión de riesgo}

El riesgo de Lavado de Activos y Financiación del Terrorismo (LAFT) se refiere a la posibilidad de que la entidad supervisada sea utilizada para fines de lavado de activos y/o financiamiento del terrorismo. ¿Quiénes desearían utilizar a una entidad supervisada para tales fines? Pues, los lavadores de activos y aquellos que financian las actividades terroristas. Para lograr su propósito, los lavadores de activos se hacen pasar por "clientes" de la entidad supervisada. Por ello, hay que vigilar cautelosamente el acceso a admisión de clientes, porque ellos podrían ser potenciales lavadores. De allí la importancia que la 
primera línea de defensa de las entidades supervisadas sea la "Debida Diligencia del Conocimiento del Cliente" (DDC).

Y la DDC no solo debe realizarse en la fase de admisión, sino también a través de un monitoreo continuo a las operaciones que realice el cliente, y la obligación de la entidad es disponer de medios, que le permitan detectar señales de alerta que podrían significar que el cliente este realizando actividades relacionadas a LAFT, y de concluirse que las operaciones son sospechosas, deberán ser reportarlas a UIF-Perú.

Ahora, la relación entre el "cliente" y la entidad supervisada se materializa en la adquisición de los "productos o servicios" que ofrece la entidad. Para ello, la entidad supervisada ofrece sus productos o servicios a través de diferentes "canales de distribución" (online, telefónico, presencial, etc.).

Los productos o servicios que son más riesgosos que otros en materia de Prevención del Lavado de Activos y del Financiamiento del Terrorismo (PLAFT) son las operaciones privadas en el mercado extrabursátil, las operaciones de banca privada de inversión, los fondos privados de inversión; son más riesgosos porque son mercados más opacos o menos transparentes en términos de la calidad y cantidad de información disponible, y a menor información mayor riesgo.

Ahora, las entidades supervisadas también operan en diferentes ubicaciones o zonas geográficas y cada una de ellas tienen mayor o menor riesgo de LAFT en la medida que el territorio en el que operen esté vinculado en actividades de LAFT. De allí que las zonas de frontera, las zonas terroristas o los paraísos fiscales sean considerados de mayor riesgo.

Cuando una persona natural o jurídica desea negociar en el mercado de valores, adquiriendo diferentes instrumentos financieros, es factible que tenga un vasto portafolio, este constante negociar, comprar, vender, invertir implica exponerse a un riesgo, por ello uno debe identificarlos y medirlos, porque no solo las personas naturales estamos expuestos a ese riesgo, las personas jurídicas también lo están, por ello empresas provisionan riesgos en su balance, para cubrirse de los efectos negativos de una perdida. 
Para Martínez Ponce de León (2002) el riesgo es la combinación de frecuencia o probabilidad y las consecuencias de un acontecimiento peligroso específico. (p.23). Dentro del riesgo existe la posibilidad de que ocurra un evento no esperado que nos genere pérdida de valor.

Es en este contexto, cuando el mundo moderno exige cada vez mayores cambios y esos cambios nos mantienen en constante evolución, ello, en el ámbito de negociación, origina la inquietud de averiguar cuál es la utilidad de nuestros productos y/o servicios, a qué segmento está orientado, quienes son los usuarios, cuál es el origen de los fondos, estas interrogantes nos llevan a evaluar los factores que se utilizaran, de qué manera ponderamos esos factores, qué valor deberemos asignarles y sobre todo cual sería la definición más acorde, de cliente de mayor riesgo de LAFT para el sujeto obligado.

\subsection{Deficiencias en la supervisión basado en riesgos}

Quizás la parte más complicada de una posición es defenderla, pero debemos aceptar que existen grandes deficiencias que se traslucen en informes de oficiales de cumplimiento siempre sin hallazgos ni denuncias de operaciones sospechosas que reportar.

Es en sí que contamos con un sistema infalible que evidencia que en el sector valores no encontraremos lavadores que pretendan utilizar los mecanismos explicados para convertir lo ilícito en lícito. A mi parecer existen brechas que debemos eludir y es cuestionar nuestro sistema de supervisión basado en riesgos, el primer paso para ello.

Preguntémonos cuan eficientes somos en nuestra supervisión, cuantos procedimientos sancionadores por infracciones de normas LAFT han sido iniciados desde la dación de la Resolución CONASEV Nº 030-2011-EF-94.01.1, de 09 de Mayo de 2011.

En puridad en este lapso de tiempo únicamente se iniciaron dos procedimientos sancionadores a dos sociedades agentes de bolsa, una de ellas por no designar oficial de cumplimiento y el otro procedimiento iniciado por no contar con manuales, ni designar oficial de cumplimiento en el tiempo, modo y forma establecido en la norma. 
El 9 de mayo del presente año, 2016, habremos cumplido ya 5 años de vigencia de la norma, la misma que ha sido modificada por la Resolución SMV N 007-2013- SMV-01 con fecha 25 de marzo de 2013 y de la lectura de los informes remitidos por las intermediarias el proceso de identificación, evaluación, control y monitoreo aún sigue siendo escaso, se presentan informes cuyos vencimientos semestrales son inminentes sin tener un claro norte hacia donde van y es que si el obligado o supervisado únicamente cumple con un requisito sin entender la verdadera importancia de realizar una buena prevención, no obtendremos lo que perseguimos y es que exista una activa postura del administrado y del supervisor en materia de PLAFT.

En este espectro, cabría preguntarse cómo está afrontando el Perú el riesgo de haber abierto su mercado a otros países como México-Colombia, desde el punto de vista mitigador, teniendo en cuenta que son países de alto riesgo. Si consideramos que ya es complicado supervisar in situ en el territorio nacional.

Considero que en todo proceso de supervisión se dé prioridad a aquellas empresas en los que el ciclo se determine, por el resultado, que son empresas que presentan un riesgo alto, al menos sean supervisados dos veces al año.

Se entiende que el punto objetivo en la estrategia de supervisión es velar por el cumplimiento de PLAFT bajo este supuesto se debe confirmar que la gestión de riesgo ha sido diseñada en línea con la actividad, identificación de clientes de las intermediarias y de ser posible implementar medidas correctivas donde se identifiquen debilidades.

De otro lado, en el sistema de control interno se espera que el auditor diga si está cumpliendo con lo establecido, que los alcances de la función de auditoría estén trabajando como debe, destacando los hallazgos.

Por ejemplo en el caso de una sociedad agente de bolsa calificada como la de menor riesgo. Se observó del alcance de la política de cliente no es congruente con la clasificación en el informe, cuando lo que se busca es que se establezcan estándares en los que las inspecciones sean realizadas dentro de un patrón. 
Tenemos que estar conscientes que en la autoevaluación todo está perfecto, se cumple, una vez que se determina que hay poco que revisar punto por punto, por ejemplo si hay 5 PEP y no fue clasificado?. Debemos ir más allá de esa causa, hay que focalizarse en los elementos de registro de clientes, pareciera ser que los registros son elaborados sin corroborar la información, solo cumplir por cumplir.

De acuerdo a la información estadística de la UIF-Perú, publicada en su portal, tenemos que dentro del periodo comprendido de enero 2007 a diciembre del año 2015 fueron:

Figura 2. 2

Numero de Reportes de Operaciones Sospechosas recibidos anualmente

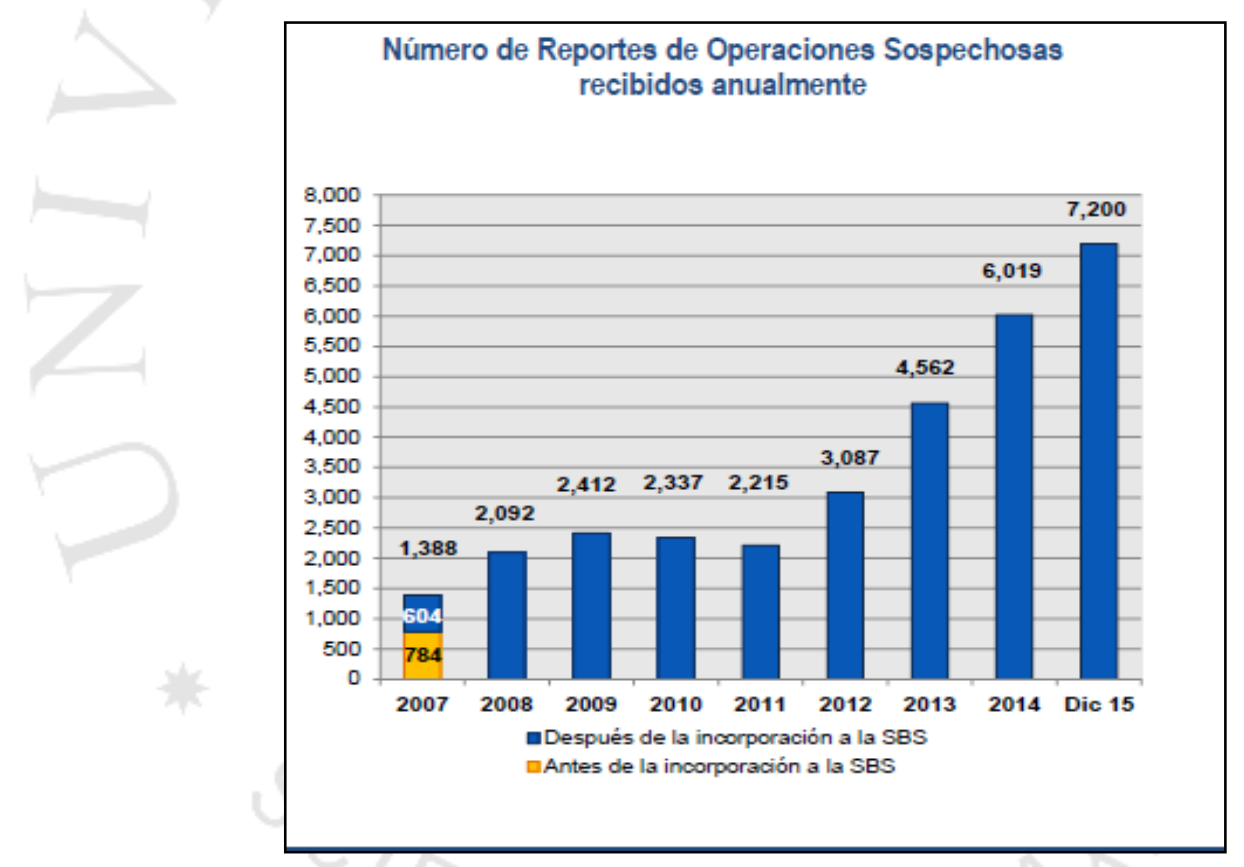

Fuente: UIF-Perú.

Y de acuerdo al reporte de operaciones sospechosas, por sujeto obligado, entre enero de 2007 a diciembre del año 2015, el 6\% corresponde a ROS originados en transacciones de Fondos Colectivos. 
Figura 2. 3

Reporte de Operaciones Sospechosas - Participación por Tipo de Sujeto Obligado - enero 2007 a diciembre

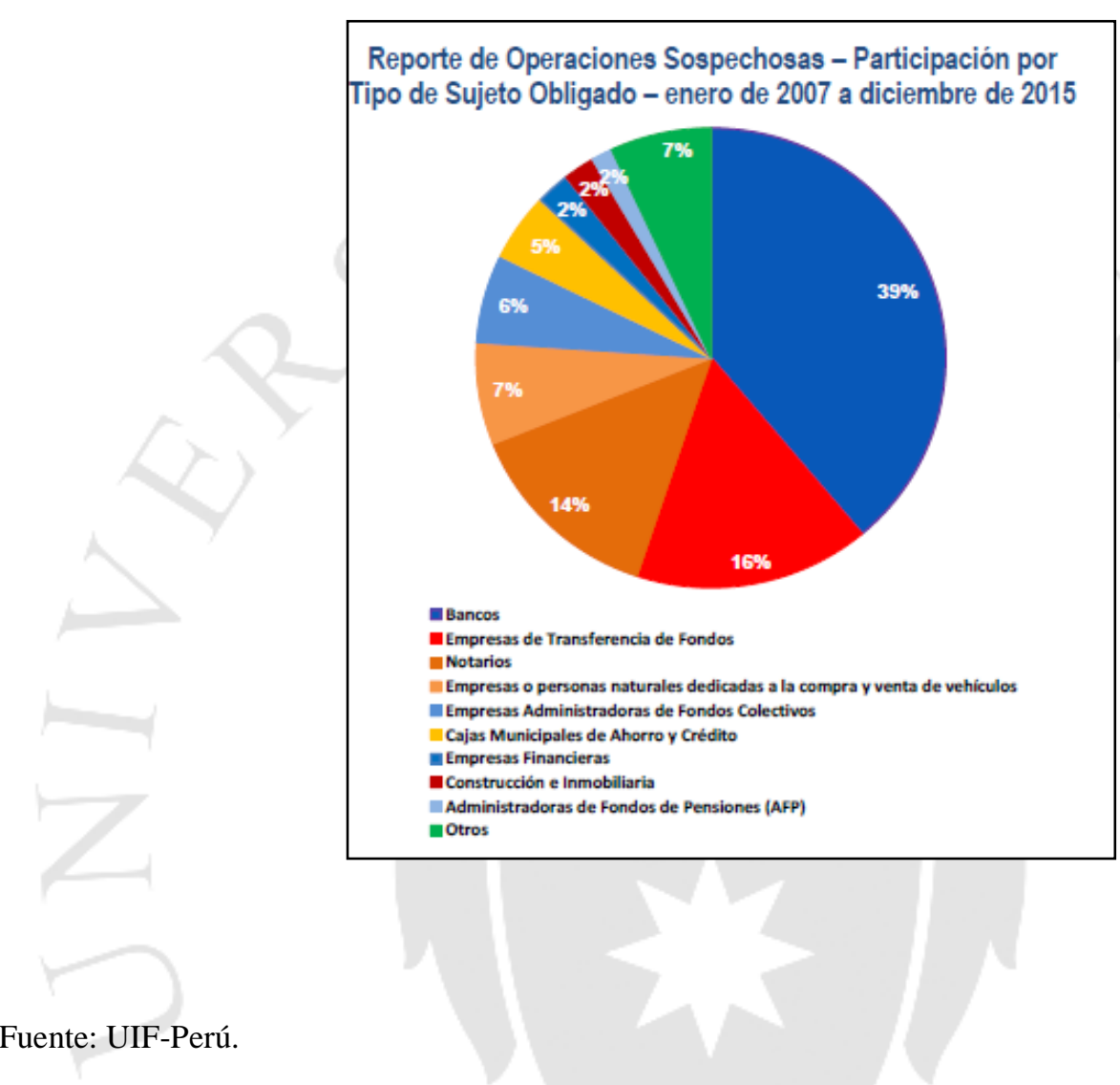

Ya en los últimos 12 meses en materia de fondos de inversión se evidenció que el 1\% del monto negociado correspondían a este rubro. 
Figura 2. 4

Reporte de Operaciones Sospechosas - Participación por Tipo de Sujeto Obligado últimos 12 meses a diciembre de 2015 .

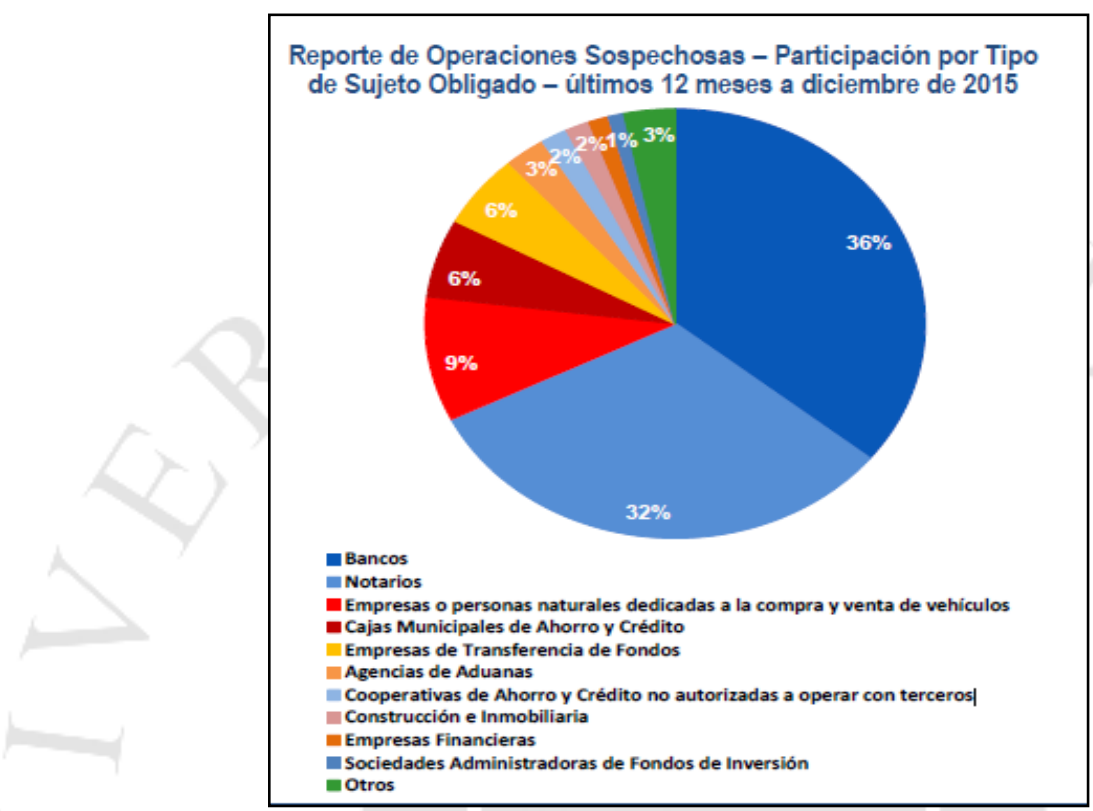

Fuente: UIF-Perú

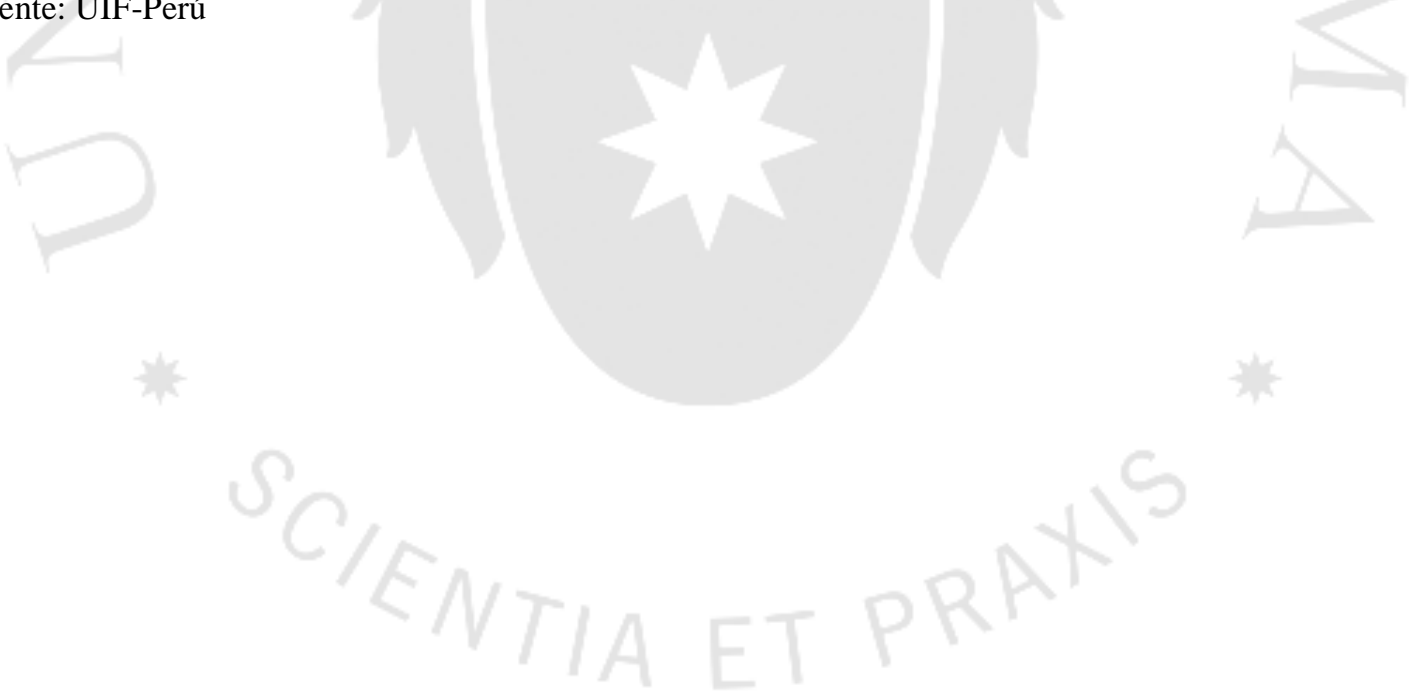




\section{CAPÍTULO III: PROPÓSITOS, BENEFICIOS Y RETOS DEL ENFOQUE BASADO EN RIESGOS}

\subsection{El GAFI y el enfoque basado en riesgos}

Las Recomendaciones del GAFI constituyen un esquema de medidas completo y consistente que los países deben implementar para combatir el lavado de activos y el financiamiento del terrorismo, así como también el financiamiento de la proliferación de armas de destrucción masiva. Los países tienen diversos marcos legales, administrativos y operacionales y diferentes sistemas financieros por lo cual no pueden tomar todos medidas idénticas contra estas amenazas. Por lo tanto, las Recomendaciones del GAFI, fijan un estándar internacional que los países deberían implementar por medio de medidas adaptadas a sus circunstancias particulares. (GAFI, 2012, p. 6)

El Perú a efectos de identificar, evaluar y mitigar los riesgos de lavado de activos, a través de la Unidad de Inteligencia Financiera, busca que los reguladores coordinen acciones para evaluar los riesgos, en virtud a ello se deberá aplicar un enfoque basado en riesgos que permita asegurar que las medidas utilizadas para mitigar los riesgos sean proporcionales a los riesgos identificados.

\subsection{Principios para el diseño de un enfoque basado en riesgos}

Para el diseño de un enfoque deberá utilizarse una metodología de calificación de riesgo que comprende:

- Elaborar una matriz.

- Comprobar la matriz contra una muestra representativa de cuentas.

- Documentar el proceso.

La evaluación de riesgo debe cuantificar los productos, transacciones, y áreas de servicio del sujeto obligado, tales como: 
- El promedio mensual de créditos en cuentas de depósito a la vista (cuentas corrientes) de clientes de alto riesgo comparado con aquellos de clientes de medio y bajo riesgo.

- El promedio mensual de transferencias electrónicas para y desde el extranjero comparado con las domésticas, etc.

- Este análisis, debe hacerse con el fin de cuantificar los riesgos existentes en todo el sujeto obligado y en toda la mezcla de transacciones del sujeto obligado.

- La evaluación de riesgos, debe incluir sistemas de mitigación de riesgos.

\subsection{Diseño de matrices de riesgo}

Se deberá cuantificar el riesgo por productos y servicios, natural/jurídica y Nacional / extranjera teniendo en cuenta:

- Cuentas de depósito a la vista (cuentas corrientes), cuentas de ahorro, etc.

- Servicios de Banca Electrónica y efectivo electrónico.

- Servicios de banca privada.

- Servicios de banca corresponsal extranjera-servicio de valija.

Cuentas "Páguese a través de".

- Productos de inversión sin depósito.

- Administración de activos y fideicomisos.

- Cuentas internas (sólo para uso del banco).

- Transacciones con giros bancarios en dólares.

- Páguese ante identidad apropiada.

- Servicio de cambio de cheques girados contra otros bancos.

El Manual de Cumplimiento para la Prevención de Lavado de Dinero y Financiamiento del Terrorismo del sujeto obligado debe ser:

- Exhaustivo. 
- Aplicabilidad y calidad de implementación.

El Personal de Cumplimiento debe ser:

- Suficiente

- Con experiencia

- Con conocimientos

- Nivel de autonomía

Figura 3. 1

Administración del Riesgo de LAFT - SABs

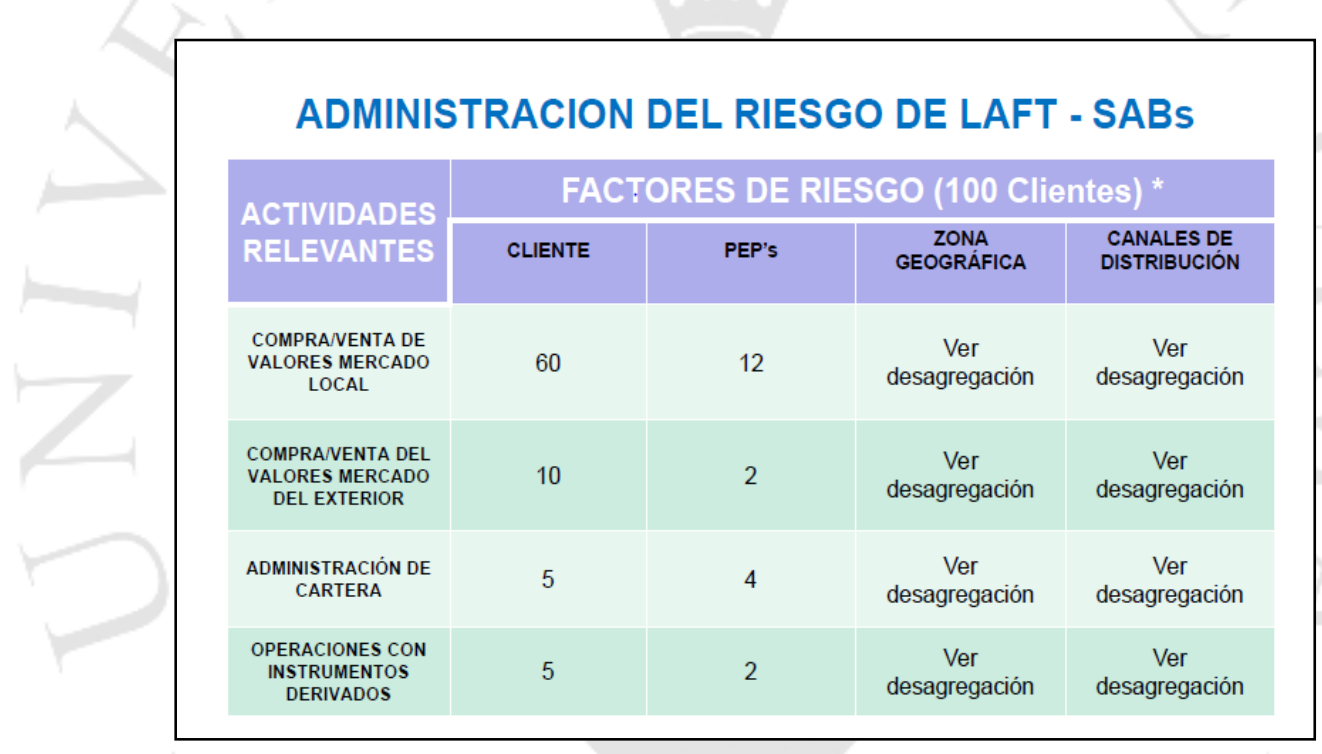

Figura 3.2

Resultados del Enfoque por riesgos para la PLAFT

\section{RESULTADOS DEL ENFOQUE POR RIESGOS PARA LA PLAFT}

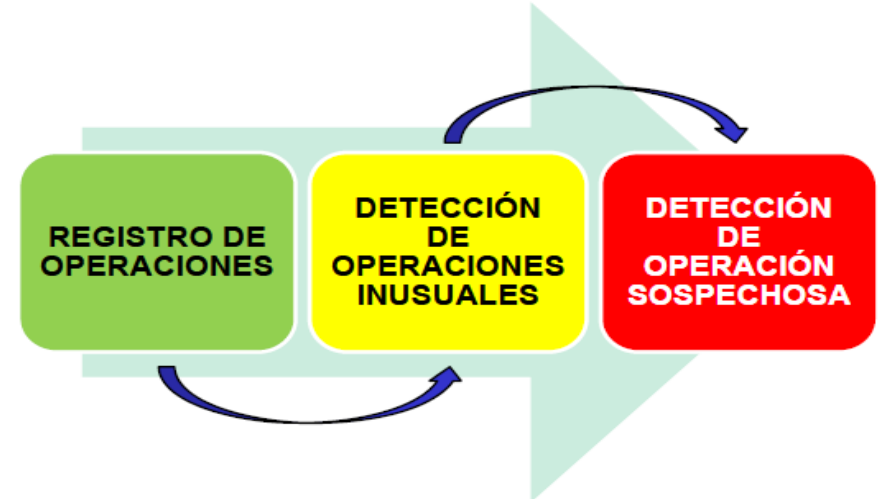

"Faro de identificación, medición, mitigación y monitoreo continúo de riesgos del Lavado de Activos" 
Figura 3.3

Administración del Riesgo de LAFT

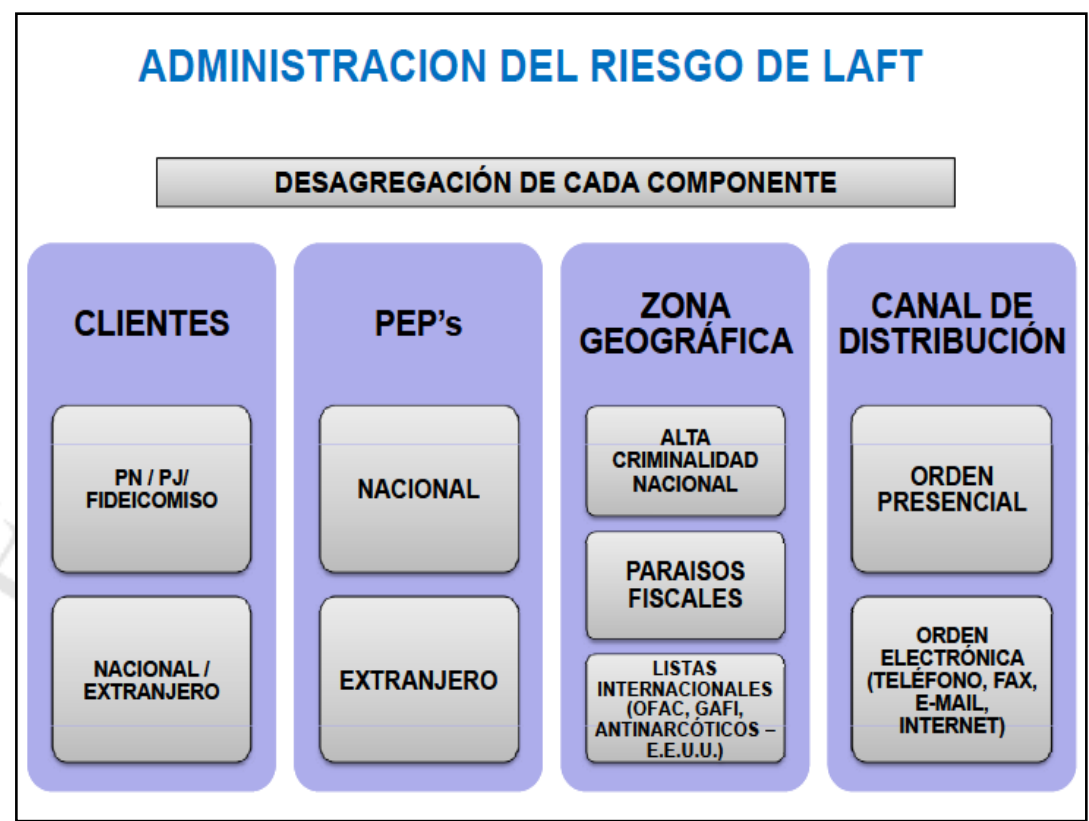

\subsection{Implementación de controles internos bajo el enfoque basado en riesgos}

Los controles internos se fundamentan en cuatro pilares de cumplimiento

1 Un sistema de control interno.

2 Un funcionario de alto nivel nombrado jefe del sistema de prevención de dinero del banco.

3 Auditorías independientes de los sistemas.

4 Capacitación, centrada en funciones, para todo el personal del banco, inclusive la gerencia y Junta Directiva.

El departamento de cumplimiento elabora los seis componentes del sistema de control interno:

Mejorando la cultura de cumplimiento.

Efectuando una evaluación de riesgo.

Desarrollando políticas, procedimientos y otros controles. 
Asegurando que las políticas, procedimientos y controles se comuniquen a todo el personal.

Asegurando que las políticas, procedimientos y controles se implementen velando por un sistema continúo de evaluación.

Es indispensable una cultura fuerte de cumplimiento.

Con frecuencia un desafío para sujetos obligados con clientes de grupos minoritarios, es que requiere de un cambio de paradigma en la cultura del personal del banco.

La Junta Directiva y la alta gerencia dan el tono de la cultura de cumplimiento con la ayuda del departamento de cumplimiento.

Los Directores de la Junta pueden no ser banqueros y no estar suficientemente familiarizados con la cultura de cumplimiento.

La cultura de cumplimiento depende del compromiso de la gerencia para fomentar la integridad y el comportamiento ético.

Cabe preguntarse cómo lograr que funcionen los controles internos?

Es definiendo claramente, y hacer cumplir, responsabilidades y roles a través de toda la organización; asegurando que cada persona corrija sus propios errores; exigiendo que cumplimiento sea uno de los factores en la evaluación del personal; instituyendo sanciones escritas para corrección de errores; identificando puntos débiles; identificando la necesidad de orientación, capacitación y sanciones e instituyendo un sistema de seguimiento y corrección de errores que permita identificar tendencias.

Para lograr una administración y control de riesgos eficiente, el sujeto obligado debe elaborar políticas, procedimientos y/procesos, y que estos incluyan separación de funciones, de niveles de autorización y procesos de revisión dichos procesos deben incluir la implementación correcta de las políticas y de los procedimientos que deben ser fluidos y deben revisarse anualmente o según corresponda.

Una vez que se hayan implementado, la Gerencia debe asegurar que las políticas, los procedimientos y los controles funcionen conforme a su diseño; controlen todos los 
riesgos pertinentes; se ajusten a todos los requisitos gubernamentales en vigor; se mantengan apropiados para las operaciones de la institución financiera y que la evaluación continua, incluya medidas oportunas para identificar y atender deficiencias, debiendo observar el componente principal de la evaluación, que es una revisión periódica por parte de auditores o consultores independientes.

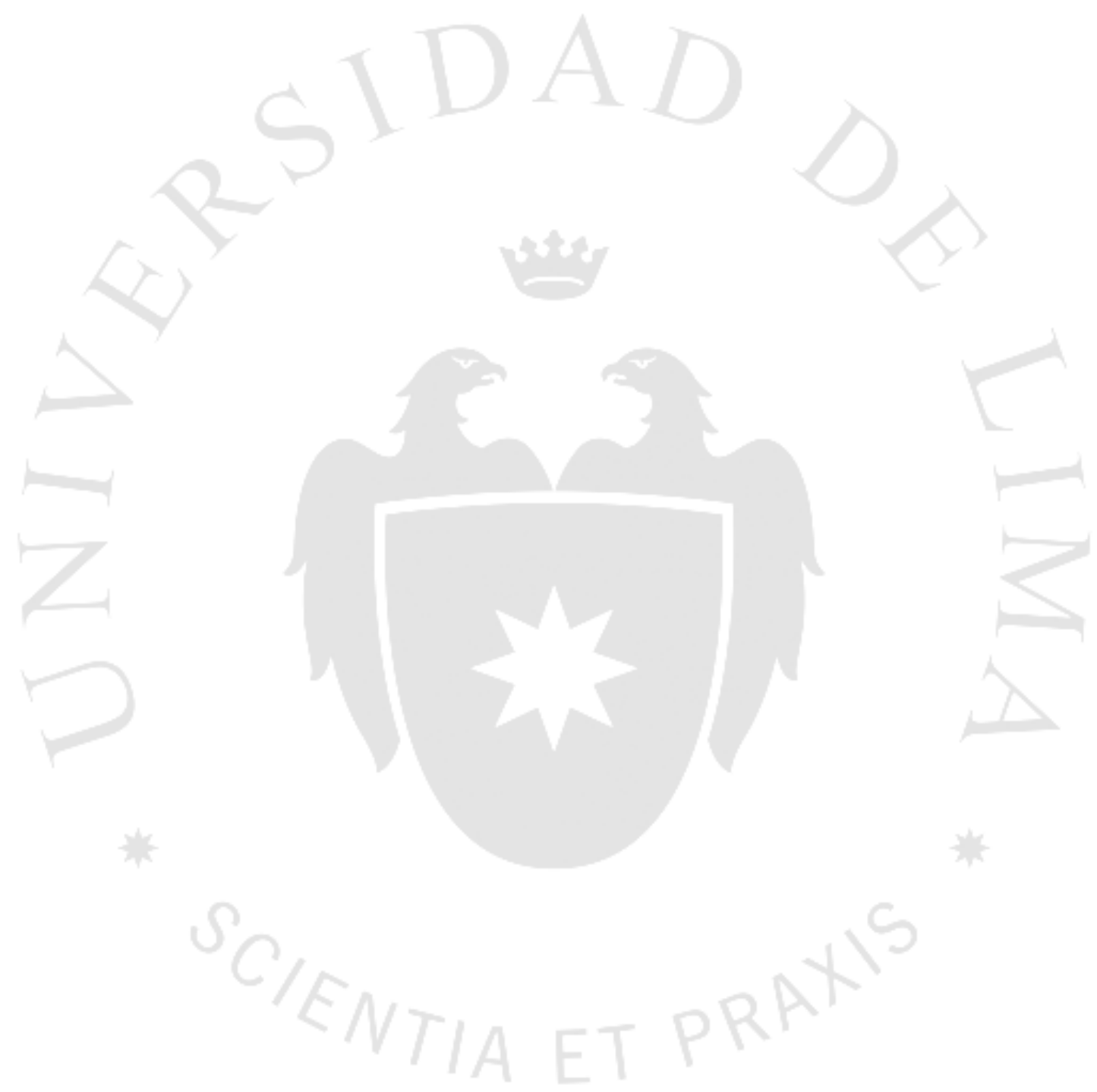




\section{CAPÍTULO IV: EL RIESGO DEL CLIENTE}

\subsection{Relevancia del Conocimiento del Cliente en el enfoque basado en riesgo}

\subsection{1 ¿Qué es la debida diligencia en el conocimiento del cliente?}

Debida Diligencia del Cliente (DDC) significa:

Obtener y conservar información específica y suficiente del cliente, elaborar un perfil del cliente, saber y entender quién es el cliente, conocer su actividad y aplicar debida diligencia del cliente a todos los clientes y a todos los productos.

Estas medidas responden a las Recomendaciones 1 y 5 del GAFI.

El GAFI señala que:

Debe prohibirse a las instituciones financieras que mantengan cuentas anónimas o cuentas con nombres obviamente ficticios.

Debe exigirse a las instituciones financieras que emprendan medidas de Debida Diligencia del Cliente (DDC) cuando:

(i) establecen relaciones comerciales;

(ii) realicen transacciones ocasionales: (i) por encima del umbral aplicable designado (USD/EUR 15,000); o (ii) están ante transferencias electrónicas en las circunstancias que aborda la Nota Interpretativa de la Recomendación 16;

(iii) existe una sospecha de lavado de activos o financiamiento del terrorismo; o

(iv) la institución financiera tiene dudas sobre la veracidad o idoneidad de los datos de identificación sobre el cliente obtenidos previamente. 
El principio de que las instituciones financieras deben llevar a cabo la DDC debe plasmarse en ley. Cada país puede determinar cómo impone obligaciones específicas de DDC, ya sea mediante ley o medios coercitivos.

Las medidas de DDC a tomar son las siguientes:

a) Identificar al cliente y verificar la identidad del cliente utilizando documentos, datos o información confiable, de fuentes independientes.

(b) Identificar al beneficiario final y tomar medidas razonables para verificar la identidad del beneficiario final, de manera tal que la institución financiera esté convencida de que conoce quién es el beneficiario final. Para las personas jurídicas y otras estructuras jurídicas, esto debe incluir que las instituciones financieras entiendan la estructura de titularidad y de control del cliente.

(c) Entender, y cuando corresponda, obtener información sobre el propósito y el carácter que se pretende dar a la relación comercial.

(d) Realizar una debida diligencia continua de la relación comercial y examinar las transacciones llevadas a cabo a lo largo de esa relación para asegurar que las transacciones que se realicen sean consistentes con el conocimiento que tiene la institución sobre el cliente, su actividad comercial y el perfil de riesgo, incluyendo, cuando sea necesario, la fuente de los fondos.

Si la institución financiera no pudiera cumplir con los requisitos aplicables en los párrafos (a) al (d) anteriores (sujeto a la modificación acorde al alcance de las medidas partiendo de un enfoque basado en riesgo), se le debe exigir a ésta que no abra la cuenta, comience relaciones comerciales o realice la transacción; o se le debe exigir que termine la relación comercial; y debe considerar hacer un reporte de transacciones sospechosas sobre el cliente.

Estos requisitos se deben aplicar a todos los clientes nuevos, aunque las instituciones financieras deben aplicar también esta Recomendación a los clientes existentes atendiendo a la importancia relativa y al riesgo, y deben llevar a cabo una debida diligencia sobre dichas relaciones existentes en los momentos apropiado" (GAFI, 2012, Recomendación $10^{\circ}$ ). 
La debida diligencia del cliente consiste en desarrollar procesos que permitan al sujeto obligado identificar al cliente, con especial atención a aquellos que por sus particulares características se presuma ser de alto riesgo.

\subsection{Determinación del perfil de riesgo del cliente}

El perfil de riesgo del cliente es una definición cuantitativa dada a un cliente determinado, sobre la asignación de uso normal de nuestros servicios en términos de volumen, cantidad y tipo de producto, directamente relacionado con su capacidad de generación y acumulación de recursos, justificación económica y procedencia de fondos.

Se analizan las características de cada segmento, se calculan rangos promedio sobre la base histórica de transacciones, se disgrega el segmento en función de características distintivas, por ejemplo, un cliente que tenga perfil de estudiante hará transacciones inferiores a S/. 1,000.00 al mes, no hará operaciones internacionales y su frecuencia transaccional es baja, al igual que una persona con perfil de pensionista, que no cuente con un patrimonio que le permita tener una actividad comercial habitual, estaría equiparada al perfil de un estudiante promedio.

\subsubsection{Clientes de alto riesgo}

- Instituciones financieras extranjeras.

- Instituciones financieras no bancarias y empresas que ofrecen servicios de remesas.

- Personas Políticamente Expuestas (PEPs).

- Extranjeros.

- Compañías privadas de inversión, fondos mutuos.

- Corredores de depósitos y préstamos.

- Negocios con alto volumen de dinero en efectivo.

- Proveedores de servicios profesionales (administran el dinero de otras personas).

- Organismos no gubernamentales (ONG). 


\subsubsection{Personas políticamente expuestas}

El GAFI define a las Personas Expuestas Políticamente (PEP) como:

Los individuos que desempeñan o han desempeñado funciones públicas destacadas en un país extranjero, por ejemplo, jefes de Estado o de gobierno, políticos de alta jerarquía, funcionarios gubernamentales, judiciales o militares de alta jerarquía, altos ejecutivos de empresas estatales, funcionarios importantes de partidos políticos. Las relaciones comerciales con los miembros de las familias o asociados cercanos de las PEP involucran riesgos en cuanto a la reputación similares a los de las mismas PEP. Esta definición no comprende a las personas de rango medio o más bajo de las categorías precitadas.

Esta definición comprende sólo a los clientes que desempeñan funciones públicas en un país "extranjero". Por tanto, no se aplica a las PEP "nacionales". Sin embargo, el GAFI alienta a los países a hacer extensivos los requisitos de una mayor debida diligencia a las personas que ocupan funciones públicas destacadas en su propio país, pero exige que se aplique una mayor debida diligencia a los PEP extranjeros (GAFI, 2012, Recomendación $6)$.

Cuando se investiga a una persona políticamente expuesta, deberá recabarse información que nos permita determinar:

¿Cuál es el país de origen de la persona y con qué información contamos de su carrera política? Investigar la historia laboral de la persona;

¿Qué información se tiene acerca de la ubicación o residencia de la persona, se debe consultar información pública disponible del país de origen;

¿La persona tiene o tuvo una posición de alto nivel en los temas políticos, operacionales o uso de recursos de propiedad del gobierno?

¿Cuáles son las responsabilidades que como funcionario del gobierno realiza la persona?

La naturaleza del cargo. 
Acceso a los fondos y/o bienes del gobierno.

¿Cuál es el propósito de la cuenta?, ¿Están acorde al propósito y origen de los fondos y del patrimonio del cliente?

\subsection{Procedimientos de debida diligencia reforzada}

Las medidas adicionales de debida diligencia consisten en lo siguiente:

- Identificar a las PEP;

- Obtener la aprobación de los directivos de mayor jerarquía para abrir una cuenta;

- Establecer cuál es el origen de la riqueza y de los fondos; y,

- Llevar a cabo una vigilancia permanente más exhaustiva.

En realidad, descubrir si un cliente es una PEP es, por lo general, el mayor desafío para una institución financiera, dada la definición del término. Ninguna organización oficial publica una lista de dichos individuos, pero diversas entidades comerciales mantienen y actualizan regularmente ese tipo de listas. (Schott, 2007, p. 89)

\subsubsection{Clientes sin presencia física}

A medida que la tecnología avanza, el fenómeno de las relaciones comerciales y los clientes sin presencia física aumenta, ya que los clientes usan el teléfono y la Internet para obtener servicios financieros sin visitar necesariamente al proveedor. Los organismos que fijan los estándares internacionales no pretenden impedir dichos adelantos, que brindan al cliente más opciones y servicios, y benefician al mismo tiempo la economía. Las instituciones financieras y otras que proveen dichos servicios deben saber que los riesgos de lavado de activos y financiamiento del terrorismo son algo diferentes con respecto a estos clientes y necesitan tomar las medidas necesarias para tratar con ellos (GAFI, 2012, Recomendación 18). 


\section{CONCLUSIONES}

- La gestión de la Superintendencia del Mercado de Valores debe estar orientada a identificar vulnerabilidades a efectos de proteger el mercado de valores de usos indebidos.

- El objetivo principal de la SMV en su labor de supervisión del sistema de prevención del LAFT es asegurar que los procesos de administración de riesgos del LAFT de los sujetos obligados, existan y estén funcionando.

- La gestión de riesgos es una manera eficaz y eficiente de prevenir que el sujeto obligado sea utilizado directa o indirectamente para lavar activos. Este proceso asegura la asignación de los recursos escasos de personal, infraestructura y tecnología de la manera más eficaz. El objetivo del sujeto obligado no es identificar o investigar al criminal, sino es identificar actividades u operaciones inusuales en la relación comercial con sus clientes, y decidir, si fuera el caso, reportar una operación sospechosa a la UIF-Perú. 


\section{REFERENCIAS}

Arbulú Ramírez, J. A. (2014). Lavado de activos, prevención, detención y control. Lima: Legales.

Decreto Legislativo $\mathrm{N}^{\circ}$ 861. Texto Único Ordenado de la Ley del Mercado de Valores. Recuperado del sitio de internet de la Superintendencia del Mercado de Valores: http://www.smv.gob.pe/index.aspx

Decreto Ley $N^{\circ}$ 26126. Texto Único Ordenado de la Ley Orgánica de la SMV. Recuperado del sitio de internet de la Superintendencia del Mercado de Valores: http://www.smv.gob.pe/index.aspx

Grupo de Acción Financiera Internacional. (s.f.). ¿Quiénes somos? Obtenido de Recuperado del sitio de internet de la Superintendencia del Mercado de Valores: http://www.smv.gob.pe/index.aspx

Grupo de Acción Financiera Internacional. (2012). Las recomendaciones del GAFI: Estándares internacionales sobre la lucha contra el lavado de activos y el financiamiento del terrorismo. Obtenido de http://docplayer.es/26310-Lasrecomendaciones-del-gafi.html

Grupo de Acción Financiera Latinoamericana. (2014). Estándares internacionales sobre la lucha contra el lavado de activos, el financiamiento del terrorismo y la proliferación. Autor. Obtenido de http://www.cocaineroute.eu/wpcontent/uploads/2015/08/Estandares-internacionales-sobre-la-lucha-contra-elLAFT-GAFILAT-v1.pdf

Martinez Ponce de León, J. G. (2002). Introducción al Análisis de Riesgos. México D.F.: Limusa.

Pérez Lamela, H. D. (2006). Lavado de dinero: Doctrina y práctica sobre la prevención e investigación de operaciones sospechosas. Buenos Aires: Lexis Nexis.

Prado Saldarriaga, V. R. (2007). Lavado de activos y financiación del terrorismo. Lima: Grijley.

Resolución Conasev N 033-2011-EF/94.01.1. Normas para la Prevención del Lavado de Activos y Financiamiento del Terrorismo. Recuperado del sitio de internet de la Superintendencia del Mercado de Valores: http://www.smv.gob.pe/index.aspx 
Schott, P. A. (2007). Guía de referencia para el antilavado de activos y la lucha contra el financiamiento del terrorismo. Bogotá: Banco Mundial. Retrieved from http://siteresources.worldbank.org/INTAML/Resources/RefrenceGuideSpanish.pdf

Unidad de Inteligencia Financiera del Perú. (2006). El lavado de activos y el financiamiento del terrorismo en el Perú [2003/2006]: desarrollo y consolidación de la Unidad de Inteligencia Financiera del Perú. Lima.

Unidad de Información y Análisis Financiero (2014). La Dimensión Económica del Lavado de Activos. ( $2^{\circ} \mathrm{a}$ ed.) Colombia: UIAF. Recuperado de:

http://www.urosario.edu.co/observatorio-de-lavado-de-activos/Archivos_Lavados/Ladimension-economica-del-LA.pdf 